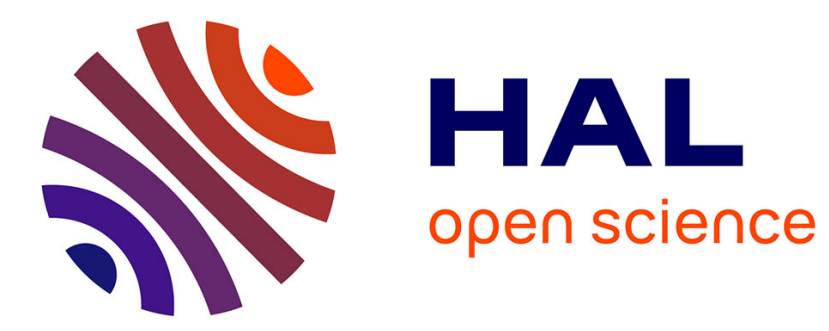

\title{
Imaging a near-surface feature using cross-correlation analysis of multi-channel surface wave data
}

Kevin Samyn, Adnand Bitri, Gilles Grandjean

\section{To cite this version:}

Kevin Samyn, Adnand Bitri, Gilles Grandjean. Imaging a near-surface feature using cross-correlation analysis of multi-channel surface wave data. Near Surface Geophysics, 2013, 11 (1), pp.1-10. 10.3997/1873-0604.2012007 . hal-00687133

\section{HAL Id: hal-00687133 \\ https://hal-brgm.archives-ouvertes.fr/hal-00687133}

Submitted on 12 Apr 2012

HAL is a multi-disciplinary open access archive for the deposit and dissemination of scientific research documents, whether they are published or not. The documents may come from teaching and research institutions in France or abroad, or from public or private research centers.
L'archive ouverte pluridisciplinaire HAL, est destinée au dépôt et à la diffusion de documents scientifiques de niveau recherche, publiés ou non, émanant des établissements d'enseignement et de recherche français ou étrangers, des laboratoires publics ou privés. 
$1 \quad$ Imaging a near-surface feature using cross-correlation analysis of multi-

$4 \quad$ K. Samyn $^{1 *}$, A. Bitri ${ }^{1}$, G. Grandjean ${ }^{1}$

$5{ }^{1}$ BRGM, Bureau de recherches géologiques et minières, French Geological

6 Survey, Risks Department, France

7

$8 \quad{ }^{*}$ Corresponding author:

9 Kévin SAMYN

10 BRGM, Risks Department

113 Avenue Claude Guillemin BP36009 45060 Orléans Cedex 2, France.

12 Tel.: +33(0)238643454.

13 Fax: $+33(0) 238643689$.

14 E-mail address: k.samyn@brgm.fr 


\section{Abstract}

In this study, we demonstrate that cross-correlation gathers of multi-channel and multi-shot configurations provide accurate estimations of shear wave velocity (VS) perturbations from Rayleigh wave data for the reconstruction of two-dimensional (2D), high-resolution velocity distributions without requiring the systematic calculation of surface wave dispersions, as in the spectral analysis of surface waves (SASW). Data acquisition for cross-correlation analysis is similar to that for a $2 \mathrm{D}$ seismic common midpoint reflection survey. The data processing involved is similar to the coda wave interferometry used for seismological data but differs in the sense that the cross-correlation of the original waveform is calculated for active source seismic data. Data processing in cross-correlation analysis consists of the following three steps: First, crosscorrelations are calculated for every trace in each shot gather with the same offset trace as a reference shot to flatten the linearly sloping events of surface waves. A common receiver location stack section can then be obtained, which allows for the assessment of lateral variations in the elastic properties of the medium. Second, the maxima of the time-shifted cross-correlation gathers and the maxima of the shot gathers' envelope traces are picked for different frequencies, and trace values having the same receiver location are averaged to calculate Vs perturbations, as described in the theory of coda wave interferometry. Finally, a 2D Vs profile is reconstructed by applying the lateral Vs perturbation to a homogeneous Vs velocity profile obtained by inversion of the surface wave dispersion of the reference shot gather. Analyses of waveform 
40 data from numerical modelling and field observations indicate that this new

41 method is valid and greatly improves the accuracy and resolution of near-

42 surface imagery using surface waves and reconstructed subsurface velocity

43 distributions compared with a conventional SASW or multi-channel application.

44

45 Keywords

46 surface wave, cross-correlation, shear-wave velocity (Vs)

47 
The delineation of shear wave velocity (Vs) structures down to a depth of approximately $30 \mathrm{~m}$ is of fundamental interest in engineering and environmental problems. P-wave and S-wave (PS) velocity logging has been adopted for this purpose for a number of years. The expense of drilling a borehole and operating a logging tool has led to a demand for more convenient methods for determining shallow surface wave structures. It is well known that the dispersion of the phase velocities of surface waves is mainly determined by the ground structure. The use of surface waves for near-surface delineation has been the subject of many studies in the past decade. For example, the spectral analysis of surface waves (SASW) has been used for the determination of 1D Vs structures down to a depth of 100 m (Nazarian et al. 1983; Stokoe et al. 1989; Grandjean and Bitri 2006). The majority of the surface wave methods described to date employ a shaker or a vibrator as a wave source and exploit calculated phase differences between two receivers using a simple cross-correlation technique. Park et al., 1998a and Debeglia et al. (2006) also discuss the feasibility of detecting near-surface features using dynamic linear moveout (dlmo) for surface wave imagery. A multi-channel analysis of surface waves (MASW) has been proposed by several authors (Song et al. 1989; Park et al. 1999a; Xia et al. 1999). This method determines phase velocities directly from multi-channel surface wave data after applying an integral transformation to the frequency-domain waveform data. The integration directly converts time-domain waveform data (time-distance) into an image of phase velocity versus frequency 
72 (c-f). Hayashi et al. (2004) show that the accuracy and resolution of (c-f) images can be improved using common mid-point (CMP) cross-correlation analysis of multi-channel surface wave data. The MASW method is more effective than the SASW method because MASW allows the fundamental mode of Rayleigh wave dispersion to be distinguished visually from body waves and from higher modes of the Rayleigh waves. Additionally, the MASW method avoids spatial aliasing, which is a problem in the SASW method (Foti et al. 2001; Neducza 2007). Xia et al. (2005) and Miller et al. (1999) applied the MASW method to continuous-profiling shot records and delineated 2D Vs structures and their resolution to determine phase velocities at low frequencies. Importantly, Park et al. (1999a) noted that it is essential for the MASW method to use a receiver array that is as long as is practical. However, a longer receiver array can decrease the lateral resolution of a survey because the conventional MASW method provides a velocity model averaged over the total length of the array. We developed a novel method to address this trade-off. Developing an alternative to conventional surface wave methods for the determination of lateral variations in Vs structure required a unique approach based on the multichannel recording of surface waves and a cross-correlation analysis.

\section{Surface wave response to a near-surface feature}

A near-surface anomaly is defined here as a component of the near-surface materials that has elastic properties differing significantly from those of the 
remaining components, which are termed normal zones. The transition from a normal to anomalous zone may be either abrupt or gradual. During a surface waves survey, a near-surface anomaly leaves a signature of its presence in several forms on a multi-channel recording, the most common form being different phase velocities for those frequencies propagating through or near the anomaly; another form consists of differing attenuation characteristics.

In addition to differing phase velocities and attenuation characteristics, an anomaly may reveal its presence in the form of the generation of higher modes (Bath 1973; Gucunski and Woods 1991), or reflected and diffracted (Yanovskaya 1989; Sheu et al. 1988) surface waves. The generation of these higher modes is closely related to the existence of a low-velocity zone underlain by and overlying high-velocity zones (a zone of velocity inversion) (Stokoe et al. 1994), and the energy of the higher modes typically becomes more significant at high frequencies (short wavelengths) (Tokimatsu et al. 1992). Reflected and diffracted surface waves are generated when the transition from normal to anomalous zones is abrupt. All of these anomaly signature types may appear on a multichannel record when either the source or the receivers are located at or near the surface location of an anomaly.

Theoretically, surface waves cannot penetrate through a void filled with air or fluid because of the lack of shear modulus inside the void. However, considering the retrograde elliptical motion of mass underneath a roll disturbance, the surface waves that penetrate above and below the void with dimensions of elliptical motion that significantly exceed the dimensions of the 


\section{Methodology}

\section{Principles} follows:

$$
133 \quad R(\Delta t)=\frac{\sum_{i=0}^{M-m} S_{1}(i \tau) S_{2}(i \tau+m \tau)}{\left\langle S_{1}\right\rangle\left\langle S_{2}\right\rangle(M-m)}
$$
where $\mathrm{m}$ is an integer multiple of a time interval, $\tau$, such that $\Delta \mathrm{t}=\mathrm{m} \tau$ (where

To improve the lateral resolution of multichannel surface wave methods, we considered the Vs perturbation relative to a reference shot gather through the cross-correlation of Rayleigh wave shot gather data recorded at different positions along a line. Cross-correlation is a standard method of estimating the degree to which two series are correlated. The cross-correlation function, $R(\Delta t)$, represents the correlation coefficient between two seismic signals at time $t=0$, $S(0)$, and a later time $t, S(t)$. The cross-correlation function can be expressed as $0<m<M) . S_{1}(t)$ and $S_{2}(t)$ are the time-dependant surface wave signals from traces 1 and 2, respectively. Both traces comprise $M+1$ data points spanning the period from $\mathrm{t}=0$ to $\mathrm{t}=\mathrm{M} \tau .\left\langle\mathrm{S}_{1}>\right.$ and $\left\langle\mathrm{S}_{2}>\right.$ are the mean intensities of the surface wave signal in traces 1 and 2 , respectively. 
139 Herein, we compare the surface wave signals. Our goal is to determine whether 140 the two signals are correlated (i.e., fluctuating in concert) or uncorrelated 141 (fluctuating independently). In modelling the autocorrelation in time, we assume 142 that the correlation of a surface wave signal with itself decays from a perfect 143 correlation at time zero to no correlation at infinite time. For the cross144 correlation between two surface wave signals at different locations, assuming seismic source repeatability, near-surface features and near-surface Vs structures create perturbations, and the two signals then fluctuate 147 independently; thus, the correlation between them decays at a certain 148 propagation time.

149 Cross-correlation temporally correlates the intensity fluctuations of the seismic 150 traces. In cross-correlation, only pairs of coherent samples from two distinct traces appear as a positive result at time $t$, whereas fluctuations in the surface the manner in which the Vs structure varies in the near surface.

Data processing procedure

A cross-correlation analysis of surface waves (CCASW) is applied to each shot gather in the dataset. Data acquisition for the CCASW method is similar to that 
for a 2D seismic common midpoint reflection survey. The source-receiver geometry is based on the end-on spread, and both the source and the receivers move up along a survey line. The processing for the CCASW is summarised in the following:

First, cross-correlations are calculated for every trace in each shot gather along the entire seismic line using the same offset trace of a user-selected reference shot gather from the overall dataset, which is considered to be unperturbed.

The reference location is a presumably normal zone within the survey line. The cross-correlation process allows us to correct for the offset effect and therefore, to flatten the linearly sloping events of surface waves in the same way as a dlmo (Park et al. 1998a, b). All of the common receiver location traces in crosscorrelated shot gathers can then be stacked together. The above procedure achieves the following effects after stacking:

- Frequencies that have the same phase velocity as that at the reference location will have large stacked amplitudes due to constructive interference.

- For those shot gathers obtained at or near the surface location of an anomaly, cross-correlation will result in time-shifted stacked traces or weak amplitudes traces due to destructive interference.

- All of the higher modes will be attenuated through destructive interference due to their different phase velocities.

- All non-planar, body waves will be attenuated due to destructive interference because of their nonlinear occurrence on a multi-channel record or because of wrong velocities used for moveout correction. 
- All reflected surface waves will appear as diffractions in the final stack section.

- Random noise will be attenuated.

187 When the stacked traces are displayed, all of the normal zones will show large amplitudes, and the anomalous zones will be denoted by diffractions, attenuated amplitudes or time-shifted events. Such a stack section is thus a good method to obtain an initial view of the lateral variations in elastic properties along the survey line.

To quantify the observations made on the stack section, we then applied coda wave interferometry to our active source survey, stipulating that a homogeneous relative change in seismic velocity, $d v / v$, results in a time-shift $d t$ (Snieder et al. 2002; Wegler and Sens-Schönfelder 2006) of:

$196 d t=-t \frac{d v}{v}$

197 For this purpose, the maxima of the cross-correlated gather is then picked to obtain the travel-time perturbation $d t$, and the maxima of the shot gather's envelope traces are used to obtain the surface wave travel time, $t$. The trace 200 envelope is an attribute of seismic traces computed using the function suattributes of the Seismic Unix (SU) package and corresponds to the envelope amplitude of the trace.

These two variables are inserted into equation (2) to calculate the Vs perturbations $d v / v$. The $V s$ perturbations with the same receiver location are averaged. A Vs profile is reconstructed by applying the velocity perturbation 
model at different frequencies to a homogeneous Vs profile obtained by inversion of the surface wave dispersion of the reference shot gather.

208

\section{Numerical modelling}

210

211 Two numerical tests were performed to evaluate the proposed method. Fig. 1 212 shows the source-receiver configuration used for data acquisition. Fig. 2 shows 213 the velocity models used for numerical modelling. Both directions of the moving214 source observations of surface waves on the survey line were tested. The two models are composed of a homogeneous half-space with $\mathrm{Vp}=1200 \mathrm{~m} / \mathrm{s}$ and

$216 \mathrm{Vs}=600 \mathrm{~m} / \mathrm{s}$ and a low-velocity, vertical and buried defect with $\mathrm{Vp}=1000 \mathrm{~m} / \mathrm{s}$ 217 and $\mathrm{Vs}=500 \mathrm{~m} / \mathrm{s}$. The Seismic Unix (SU) suea2df function (Juhlin, 1995), which 218 is based on a stress-velocity, staggered grid, 2D finite-difference method 219 (Levander, 1988; Virieux, 1986), was used for the waveform calculation. Synthetic seismic gathers were generated using a zero-phase Ricker wavelet. The finite difference calculation was performed using 321 and $2130.5 \times 0.5 \mathrm{~m}$ cells, respectively, for the $x$ and $z$ axes and 12000 samples with a sample interval of $0.1 \mathrm{~ms}$. The synthetic model size was chosen to be sufficiently large to get free from border effects. After the calculations, the data were resampled to 48 traces with $1 \mathrm{~m}$ spacing and 1000 samples with a $1 \mathrm{~ms}$ sample interval and processed using CCASW.

227 Fig. 3 presents a flow diagram illustrating the processing procedure for the synthetic shot gather data obtained through numerical modelling. Fig. 3a 
229 illustrates the cross-correlation operation for selected synthetic examples. The 230 variables $d t, t$, and $d v / v$ are highlighted in Figure 3b.

231 Figs. $4 a, 4 b$, and $4 c$ show the resultant stack section and calculated Vs 232 perturbation $(\mathrm{dv} / \mathrm{v})$ for the vertical defect synthetic model. Evident velocity 233 perturbation artefacts appear on both sides of the perturbation peak according 234 to the direction of the moving-source observation. In fact, when the source 235 location is centred on the position of the defect, the waveform is perturbed for 236 all the shot gathers even when some traces lie outside of the anomaly. To 237 remedy this phenomenon, only the maxima of both calculated Vs perturbations $238(d v / v)$ of the two moving-source datasets are retained. Fig. 4c shows that the 239 value of $d v / v$ around $-20 \%$ obtained from CCASW of the whole seismic line is 240 coherent with the inferred true Vs perturbation value of $-17 \%$, which provides a consistency check for the method.

242 To characterise the in-depth velocity perturbation, a zero-phase, sine-squared, 243 tapered band-pass filter centred on the frequencies $10 \mathrm{~Hz}$ to $45 \mathrm{~Hz}$, in 244 increments of $5 \mathrm{~Hz}$, was applied after the cross-correlation analysis. The 245 variables $d t$ and $t$ were then obtained for different frequencies of the surface 246 wave. A "pseudo-depth" for the calculated dv/v was retrieved considering the 247 approximation of the half wavelength of the surface wave (Wightman et al. 248 2003):

$$
d=0.53 \frac{V_{p h}}{f}
$$


250

251

252

253

254

255

256

257

258

259

260

261

262

263

264

265

266

267

268

269

270

271

272

where $d$ is the depth, Vph is the phase velocity of the surface wave, and $f$ is the frequency. Fig. 5 shows the $2 \mathrm{D}$ Vs profiles reconstructed by applying the calculated lateral velocity perturbation $(d v / v)$ to the homogeneous half space. Here, we observe that the CCASW allows for the reconstruction of the synthetic velocity models used for numerical modelling, and that the buried low-velocity defect is resolved using the frequency-depth conversion approximation.

\section{Field test: Detection of a buried pipe}

Data acquisition

Rayleigh wave shot gathers were acquired along a linear profile over a known buried pipe. To increase the speed and efficiency of the data recording and thereby reduce acquisition costs, a multichannel seismic cable was designed and manufactured with 24 takeouts at fixed intervals of $2 \mathrm{~m}$. Each takeout is attached to a single self-orientating, gimballed, vertical geophone with a resonance frequency of $10 \mathrm{~Hz}$. To ensure proper coupling, each gimballed geophone is housed in a heavy casing $(\sim 1 \mathrm{~kg})$. To damp the motion of the sensor around its rotational axis, the inside of the casing is filled with viscous oil. The seismic cable was towed behind a vehicle. A 24-channel seismograph was used to record the impacts of a weight-drop electronic seismic source. The source-to-nearest-receiver offset was $2 \mathrm{~m}$, whereas the source stations were separated by $10 \mathrm{~m}$ along the survey line. In this way, measurements were 
273 performed with a recovering distance, as shown in Fig. 1, between each 274 position of the seismic antenna (meaning that consecutive shots have several 275 common geophones) to improve the signal-to-noise ratio in the CCASW stack 276 section.

278 Field test: Detection of a buried karst

Geological setting

As a feasibility test of the previously outlined method, an experiment was conducted to detect a near-surface buried karst as an anomaly. The geological information is provided by 3 the geotechnical soundings performed on the investigation site (Fig. 6a):

$286 \quad-\quad$ The levee embankment consists of loamy materials and brown silt. This 287 formation extends vertically from the surface to a depth around 4-5 $\mathrm{m}$.

- A sedimentary formation is represented by the Loire River sandy alluviums and gravels. This formation extends vertically from depths between $4-5 \mathrm{~m}$ to $12-13 \mathrm{~m}$.

291 The bedrock formation is composed of differentially weathered white limestone and marls that extend to a depth around $13 \mathrm{~m}$. The presence of such easily dissolved bedrock (limestone and dolomite) near the ground surface is 294 characteristic of karst terrain. Because carbonate rocks can be dissolved by 
295

296

297

298

299

300

301

302

303

304

305

306

307

308

309

310

311

312

313

314

315

Detection of a buried pipe

Data acquisition

\section{Results}

groundwater, karst areas are often characterised by sinkholes, springs, and underground streams whereby some surface flows are lost to groundwater (Waltham et al. 2005; Halbecq 1996).

Rayleigh wave shot gathers were acquired along a linear profile at the top of a flood-protection levee along the Loire River in France (Fig. 6a). The survey site was located in a karst terrain near an area of surface collapses (Fig. 6b), which are among the known subsidence features of karst activity (Waltham et al. 2005; Halbecq 1996). The purpose of the survey was to detect potential buried karstic features at the location of the collapse. The configuration used for this field test is the same as that used for the detection of the buried pipe and for the karst investigation in Debeglia et al. (2006); Which one gave good results in detecting karstic features to a depth around 15-20 m Simultaneously, 3 geotechnical soundings (S1, S2, and S3) were performed with the aim of verifying the validity and accuracy of the CCASW method. 
317 A prerequisite to the application of the CCASW to field data was the

318 identification of a reference shot gather that was representative of an 319 unperturbed area for the survey line. The first shot gather was selected for the 320 reference as it was situated at a location where no buried pipe was indicated on 321 the pipeline plan. A CCASW stack section was then computed and a 322 conventional dlmo processing (Park et al., 1998a,b) was also applied to the 323 entire field surface wave dataset for comparison. Fig. 7 shows the comparison between the dlmo stack section (Fig. 7a) and the CCASW stack section (Fig. 7b). The buried pipe is revealed as a diffraction at $\mathrm{X}=70 \mathrm{~m}$ on both stack sections. The apex of the diffraction appears at the time $0.1 \mathrm{~s}$. Here, we see that the CCASW better resolves the diffraction and allows for improved accuracy and resolution compared with conventional dlmo imagery.

Detection of a buried karst

A prerequisite to the application of the CCASW to field data was the identification of a reference shot gather that was representative of an unperturbed area for the survey line. This selection was realised using the shape of the phase-velocity-versus-frequency (c-f) dispersion images. The $c-f$ images of the shot gathers located near $(X=280 \mathrm{~m})$ and far $(X=50 \mathrm{~m})$ from the collapse $(X=290 \mathrm{~m})$ were then compared for this purpose. The $\mathrm{c}-\mathrm{f}$ image of the shot gather located near the collapse (Fig. 8b) exhibited the generation of higher propagation modes, whereas this was not the case for the shot gather 
340 located far from the collapse (Fig. 8a). As noted previously, the generation of 341 higher modes is a good indicator of the presence of a complex medium lying 342 below the surface location of the seismic antenna. For this field test, and in many cases, we admit that the generation of higher modes in the c-f image of a 344 shot gather is an inadequate criterion for the choice of this shot gather as a 345 reference. The shot gather at location $\mathrm{X}=50 \mathrm{~m}$ was thus selected as the 346 reference shot for the study. Fig. 9 shows a shot gather located at $X=100 \mathrm{~m}$, away from the collapse, a shot gather located at $280 \mathrm{~m}$, and the respective results of cross-correlation with the reference shot gather. A perturbation can be distinguished near the collapse on the basis of the time-shifted cross-correlation (approximately $0.02 \mathrm{~s}$ ), whereas no consequent time shift is observed far from the perturbed area. CCASW processing was applied to the entire field surface wave dataset after a zero-phase, sine-squared, tapered band-pass filtering centred on the frequencies $8 \mathrm{~Hz}$ to $40 \mathrm{~Hz}$ every $2 \mathrm{~Hz}$.

We note that this study was conducted in the operational context of a project aimed at assessing Loire River levee integrity over a total distance of approximately $70 \mathrm{~km}$, and we thus did not acquire surface wave data in the two directions of the moving source observation. The calculated Vs perturbations $(d v / v)$ are then likely to be somewhat distorted compared with their true values due to the effects of moving-source artefacts, as illustrated in Fig. 4. Nevertheless, based on the numerical modelling results, we suggest that the general distribution of velocity perturbations constitutes a reasonable first-order approximation of the actual situation in the subsurface. Fig. 10 presents the resulting calculated Vs perturbation $(d v / v)$ for the $16 \mathrm{~Hz}$ frequency. Here, a Vs 
364 perturbation $(d v / v)$ of approximately $-25 \%$ appears between the locations at 250 $\mathrm{m}$ and $300 \mathrm{~m}$ and almost centred on the location of the surface collapse. The frequency-depth conversion was then applied using the half-wavelength approximation, and a 2D Vs cross-section was reconstructed by applying the lateral velocity perturbations to a 1D Vs profile obtained by a non-linear leastsquares inversion (Xia et al. 1999) of the reference shot gather dispersion curve. To ensure the correctness of reference shot gather's inversion, the authors paid attention to the fit between the observed and computed dispersion fundamental curves as in common practice in surface wave methods. A conventional MASW processing with fundamental mode inversion was also applied to the entire field surface wave dataset for comparison. Following the convention, the inverse results for each shot gather were located at the midpoint of each position of the seismic antenna. To assess the lateral variations of elastic properties with depth, the CCASW stack section was convolved with a 32-s linear sweep with frequencies decreasing from 40 to $5 \mathrm{~Hz}$. This operation has the effect of separating the different frequencies of the surface wave. The approximation.

Figs $11 \mathrm{a}, 11 \mathrm{~b}$ and $11 \mathrm{c}$ show the CCASW stack section and Vs profiles obtained from the MASW and the CCASW methods. The weathering index (A-value) curves obtained from the geotechnical soundings are superimposed on the resulting sections. This geotechnical parameter is defined as follows (Pfister 1985): 
$387 \quad A=1+\left[\frac{P O i}{P O \max }-\frac{V A i}{V A \max }\right]$

388

389

390

391

392

393

394

395

396

397

398

where Poi is the pressure on the drilling tool for depth $i, P O \max$ is the maximum pressure on the drilling tool during the sounding, $V A i$ is the velocity of the drilling tool as it progresses in the ground for depth $i$, and VAmax is the maximum velocity of the progress of the drilling tool during the sounding; A-values vary between 0 for voids and 2 for highly competent materials. A coherent, weakamplitude, low-velocity anomaly $(140-300 \mathrm{~m} / \mathrm{s})$ that trends north-west from 0 to $23 \mathrm{~m}$ depth is evident on the convolved CCASW stack and the CCASW Vs profile and is almost centred on the location of the surface collapse (X=300 m) (Fig. 11). The attenuation area is likely caused by destructive interference due to the generation of higher modes near the location of the collapse (Fig. 8b). The anomaly decreases in coherence and magnitude down to a depth of $30 \mathrm{~m}$. It is evident that the shape of the anomaly is roughly consistent with the low to very low $A$-values (0-1) from the S2 and S3 soundings, revealing the presence of highly deconsolidated materials. The A-values from $\mathrm{S} 1$, showing no dramatic values $(>1)$ of the weathering index, reveal the relative competency of the adjacent areas. The MASW Vs profile shows a vast zone with a lower Vs (approximately $450 \mathrm{~m} / \mathrm{s}$ ) between the depths of 20 and $40 \mathrm{~m}$ and a vertical shift related to the collapsing feature (Fig. 11b). This shift is likely due to the change in the shape of the fundamental mode in the $c$-f image, which trends towards lower velocities in the perturbed area compared with the reference $c-f$ image (Fig. 8). Further the velocity depression of the fundamental mode due to the presence of weathered materials, generated higher modes reveal the 
410 complexity of the area near the collapse. Nevertheless, the velocity distribution

411 obtained using the MASW does not coincide very well with the $A$-value curves, 412 especially in the 10-20 m depth interval.

\section{Discussion}

416 The geology of the studied area consists of a levee embankment (brown silt) 417 above a sedimentary formation that is composed of gravels and sand based on a white limestone bedrock. The CCASW stack section and CCASW Vs profile respectively reveal a weak amplitude and low velocities (approximately 140$300 \mathrm{~m} / \mathrm{s}$ ) in an area between 0 and $23 \mathrm{~m}$ deep at the location $\mathrm{X}=300 \mathrm{~m}$, likely representing the complexity of the unconsolidated near surface weathered materials. The model presents significantly higher velocities in the adjacent areas. The low field velocities in the CCASW Vs profile likely result from the presence of a karstic collapse below a northwest-trending epikarst created by the flow of sediments into the karstic cavity. The MASW Vs profile shows poor agreement with the actual situation of the subsurface given by the $A$-value curves, indicating that the CCASW method greatly improves upon the accuracy and resolution of the reconstructed subsurface Vs distribution compared with the conventional surface wave methods with fundamental mode inversion. However, we note that this study considers only the fundamental mode and that the MASW Vs profile resolution could be improved when considering the recent achievements in the accurate assessment of Vs profiles using surface wave 
433 methods. For example, further studies should compare the results of the

434 CCASW method with the multimode inversion results of $c$ - $f$ images or joint 435 inversion using the effective dispersion of surface waves (Hamimu et al. 2010).

\section{Conclusions}

439 The study presents the CCASW method, a novel approach to seismic imaging 440 based on the cross-correlation analysis of multi-channel surface wave data. 441 This method allows for high-resolution surface wav imagery and the accurate estimation of Vs perturbations and enables the reconstruction of twodimensional subsurface Vs distribution with high resolution without requiring the systematic processes of multichannel spectral analysis of surface waves: the computation of dispersion images and the picking and inversion of dispersion curves. The overall performance of the newly developed method in this study, demonstrates that it is a simple, reliable, and very sensitive technique for characterising lateral variations in near-surface mechanical properties. This method should be applicable to the detection of a variety of subsurface defects

450 (e.g., voids, karsts, or structural heterogeneities). The applicability of this model extends to the characterisation of material properties, integrity assessment, and surface profiling in many types of geotechnical and environmental studies. Our analyses of waveform data derived from numerical modelling and field observations indicate that the CCASW method is valid as an operational sounding method and provides strong inputs for characterisation studies of 
near-surface features that allow for improved accuracy and resolution compared 457 with conventional surface wave methods.

458

Acknowledgements

460

461 The study was financed by the French Research and Environment ministry. The 462 authors thank the technicians of the BRGM for acquiring the seismic data. 463 Finally, the authors thank the Near Surface Geophysics Editors, Barbara Luke 464 and an anonymous reviewer for their comments and suggestions that led to a 465 much-improved manuscript.

466 
Bath, M. 1973. Introduction to seismology. John Wiley and Sons, New York.

Debeglia N., Bitri A. and Thierry P. 2006. Karst investigations using microgravity and MASW; Application to Orléans, France. Near Surface Geophysics 4, 215225.

472 Foti, S., Lancellotta, R., Socco, L. V. and Sambuelli, L. 2001. Application of FK 473 analysis of surface waves for geotechnical characterization. Fourth International 474 Conference on Recent Advances is Geotechnical Earthquake Engineering and 475 Soil Dynamics and Symposium in Honor of Professor W. D. Liam Finn, San 476 Diego, California, March 26-31, 2001.

477 Grandjean, G. and Bitri, A. 2006. 2M-SASW: inversion of local Rayleigh wave 478 dispersion in laterally heterogeneous subsurfaces: application to Super-Sauze 479 landslide (France). Near Surface Geophysics,4, 215-225.

480 Gucunski, N. and Woods, R. D. 1991. Instrumentation for SASW testing In: 481 Geotechnical Special Publication No. 29, Recent Advances in Instrumentation, 482 Data Acquisition and Testing in Soil Dynamics (eds. S. K. Bhatia and G. W. 483 Blaney), pp. 1-16. American Society of Civil Engineers.

484 Halbecq, W. 1996. Approche géomorphologique des brèches dans les levées 485 de la Loire (Geomorphologic approach of breaches in Loire levees). Phd thesis. 486 Orléans, Université d'Orléans.(in French).

487 Hamimu, L., Safani, J. and Nawawi, M. 2010. Improving the accurate 488 assessment of a shear-wave velocity reversal profile using joint inversion of the 
489 effective Rayleigh wave and multimode Love wave dispersion curves. Near 490 Surface Geophysics 9, 1-14.

491 Hayashi, K. and Suzuki, H. 2004. CMP cross correlation analysis of multi492 channel surface wave data. Exploration Geophysics 2004 35, 7-13.

493 Juhlin, C. 1995. Finite-difference elastic wave propagation in 2D heterogeneous 494 transversely isotropic media. Geophysical Prospecting 43(6), 843-858.

495 Levander, A.R. 1988. Fourth-order finite-difference P-SV seismograms: 496 Geophysics 53, 1425-1436.

497 Miller, R.D., Xia, J., Park, C.B. and Ivanov, J.M. 1999. Multichannel analysis of 498 surface waves to map bedrock: The Leading Edge 18, 1392-1396.

499 Nazarian, S., Stokoe, K.H. and Hudson, W.R., 1983. Use of spectral analysis of 500 surface waves method for determination of moduli and thickness of pavement 501 system. Transportation Research Record 930, 38-45.

502 Neducza, B. 2007. Stacking of surface waves, Geophysics 72, V51.

503 Park, C. B., Miller, R. D., and Xia, J., 1998a, Ground roll as a tool to image 504 near-surface anomaly:, Society Of Exploration Geophysicists, Annual Meeting 505 Abstracts, 874-877.

506 Park, C.B., Miller, R.D. and Xia, J. 1998b, Imaging dispersion curves of surface 507 waves on multi-channel record:, Society Of Exploration Geophysicists, Annual 508 Meeting Abstracts, 1377-1380. 
509 Park, C.B., Miller, R.D. and Xia, J., 1999a, Multimodal analysis of high 510 frequency surface waves. In: Proceedings of the Symposium on the Application 511 of Geophysics to Engineering and Environmental Problems '99, pp. 115-121.

512 Park, C.B., Miller, R.D. and Xia, J. 1999b, Multichannel analysis of surface 513 waves. Geophysics 64, 800-808.

514 Pfister, P. 1985. Recording drilling parameters in ground engineering. Ground 515 Engineering 18(3), 16-21.

516 Sheu, J.C., Stokoe II, K.H. and Roesset, J.M. 1988. Effect of reflected waves in 517 SASW testing of pavements. Transportation Research Record No. 1196, 51-61.

518 Snieder. R., Grêt, A., Douma, H. and Scales, J. 2002. Coda wave 519 interferometry for estimating nonlinear behavior in seismic velocity, Science $520 \quad 295,2253-2255$.

521 Song, Y.Y., Castagna, J.P., Black, R.A. and Knapp, R.W. 1989. Sensitivity of 522 near-surface shear-wave velocity determination from Rayleigh and Love waves. Technical program with Biographies, SEG, 59 ${ }^{\text {th }}$ Annual Meeting, Dallas, TX, 509-512.

Stokoe II, K.H., Wright, G.W., James, A.B. and Jose, M.R. 1994. 526 Characterization of geotechnical sites by SASW method. In: Geophysical 527 characterization of sites, ISSMFE Technical Committee \#10 (ed. R.D. Woods), 528 Oxford Publishers, New Delhi.

529 Stokoe II, K.H., Rix, G.J. and Nazarian, S. 1989. In situ seismic testing with surface wave. In: Proceedings of the XII International Conference on Soil Mechanics and Foundation Engineering, pp. 331-334. 
532 Tokimatsu, K., Tamura, S. and Kojima, H. 1992. Effects of multiple modes on

533 Rayleigh wave dispersion characteristics. Geotechnical Engineering 118(10), $534 \quad 1529-1543$.

535 Virieux, J., 1986. P-SV wave-propagation in heterogeneous media: velocity536 stress finite-difference method. Geophysics 51, 889-901.

537 Xia, J., Miller, R.D. and Park, C.B. 1999. Estimation of near-surface shear-wave 538 velocity by inversion of Rayleigh waves. Geophysics 64, 691-700.

539 Xia, J., Chen, C., Tiang, G., Miller, R.D. and Ivanov, J. 2005. Resolution of high540 frequency Rayleigh-wave data. Journal of Environmental and Engineering 541 Geophysics 10(2), 99-110.

542 Waltham, T., Bell, F.G., Culshaw, M.G. 2005. Sinkholes and Subsidence, Karst 543 and Cavernous Rocks in Engineering and Construction Series. Springer, UK.

544 Wegler, U. and Sens-Schönfelder, C. 2006. Fault zone monitoring with passive 545 image interferometry. Geophysical Journal International 168, 1028-1033.

546 Wightman, W.E., Jalinoos, F., Sirles, P. and Hanna, K. 2003. Application of 547 Geophysical Methods to Highway Related Problems. Federal Highway 548 Administration, Central Federal Lands Highway Division, Lakewood, CO, 549 Publication No. FHWA-IF-04-021.

551 Yanovskaya, T.B. 1989. Surface waves in media with weak lateral 552 inhomogeneity. In: Modern approaches in geophysics vol. 9, Seismic surface waves in a laterally inhomogeneous earth (ed. V.I. Keilis-Borok), pp. 35-70. 
557 Fig. 1 The source-receiver geometry used in the numerical tests. Both directions of the moving-source observation of surface waves were tested. The shot positions for the gathers shown in Fig. 3 are highlighted.

560

Fig. 2 The Vs models used for the numerical tests. The locations of the seismic antenna for the gathers shown in Fig. 3 are highlighted.

Fig. 3 A diagram illustrating the processing of surface wave data. a) Examples of the calculation of cross-correlations from the traces of a perturbed and an unperturbed shot gather with the same offset trace of the reference shot gather. In the unperturbed case, the cross-correlations are centred on the time $0 \mathrm{~s}$. In

568 the perturbed case, the cross-correlations show a travel-time perturbation of approximately $0.01 \mathrm{s.} \mathrm{b)} \mathrm{Illustration} \mathrm{of} \mathrm{the} \mathrm{calculation} \mathrm{of} \mathrm{the} \mathrm{Vs} \mathrm{perturbation}$ $(d v / v)$ using equation (2) and the variables $d t$ and $t$, which are highlighted by white dotted and solid lines, respectively. In the perturbed case, the Vs

572 perturbation is approximately $-10 \%$ between traces 30 and 48 .

574 Fig. 4 a) A left-right moving source CCASW stack section for the vertical defect model. b) The calculated Vs perturbations $(d v / v)$ for both moving-source

576 directions. Velocity perturbation artefacts appear on the sides of the 577 perturbation peak; c) The calculated Vs perturbation $(d v / v)$ using only the 
578 maxima of the calculated $d v / v$ of the two moving-source datasets. The black 579 solid line marks the real velocity perturbation of the model.

580

581

Fig. 5 The Vs profiles obtained by CCASW processing of the data obtained through numerical modelling of the synthetic models shown in Fig. 2. The locations of the seismic antenna for the gathers shown in Fig. 3 are highlighted.

Fig. 6 a) An aerial photograph of the survey site. The black solid line denotes 586 the seismic survey line near the Loire River (France). The red dots mark the locations of the geotechnical soundings (S1, S2 and S3). b) A photograph of the collapse at the top of the flood-protection levee.

Fig. 7. A comparison of the a) dlmo stack section and b) CCASW stack section computed for field data recorded over the buried pipe. Here, we see that the diffraction due to the buried pipe is better resolved by the CCASW stack section.

Fig. 8 A comparison of the $c$ - $f$ images of shot gathers located a) far from $(X=50$

$\mathrm{m})$ and $\mathrm{b})$ near $(X=280 \mathrm{~m})$ the collapse $(X=290 \mathrm{~m})$. The reverse triangle marks the location of the surface collapse, and the black solid and black dotted lines respectively indicate the fundamental and higher propagation modes of the surface waves. The $c-f$ image of the shot gather located near the collapse exhibits the generation of higher propagation modes, although this is not the 
601

602

603

604

605

606

607

608

609

610

611

612

613

614

615

616

617

618

619

620

621

622

623

624

case for the shot gather located far from the collapse. The shot gather at $X=50$ $\mathrm{m}$ was selected as the reference shot for the study. The shot positions of the gathers shown in Fig. 9 are highlighted.

Fig. 9 The calculation of cross-correlations from traces of the unperturbed shot gather (located at $X=100 \mathrm{~m}$ ) and the perturbed shot gather (located at $X=280 \mathrm{~m}$, near the location of the collapse at $X=290 \mathrm{~m}$ ) with the same offset trace from the reference shot gather (located at $X=50 \mathrm{~m}$ ). In the unperturbed case, the cross-correlations are centred on the time $0 \mathrm{~s}$. In the perturbed case, the crosscorrelations show a travel-time perturbation of approximately $0.02 \mathrm{~s}$.

Fig. 10 The calculation of Vs perturbations $(d v / v)$ using Equation (2) for the entire field surface wave dataset and for the $16 \mathrm{~Hz}$ frequency. A Vs perturbation of approximately $-20 \%$ appears in the area surrounding the collapse.

Fig. 11 a) The convolved CCASW stack section. b) Vs profile defined by the MASW method. c) Vs profile defined by the CCASW method. The A-value curves overlay the profiles as solid black lines. The triangle marks the location of the surface collapse. The area of attenuated amplitudes in the convolved CCASW stack section is outlined by the dotted black line overlaying the Vs profiles. Here, it is evident that the shape of the weak-amplitude area on the CCASW stack section matches well with the low-velocity anomaly in the CCASW Vs profile. 


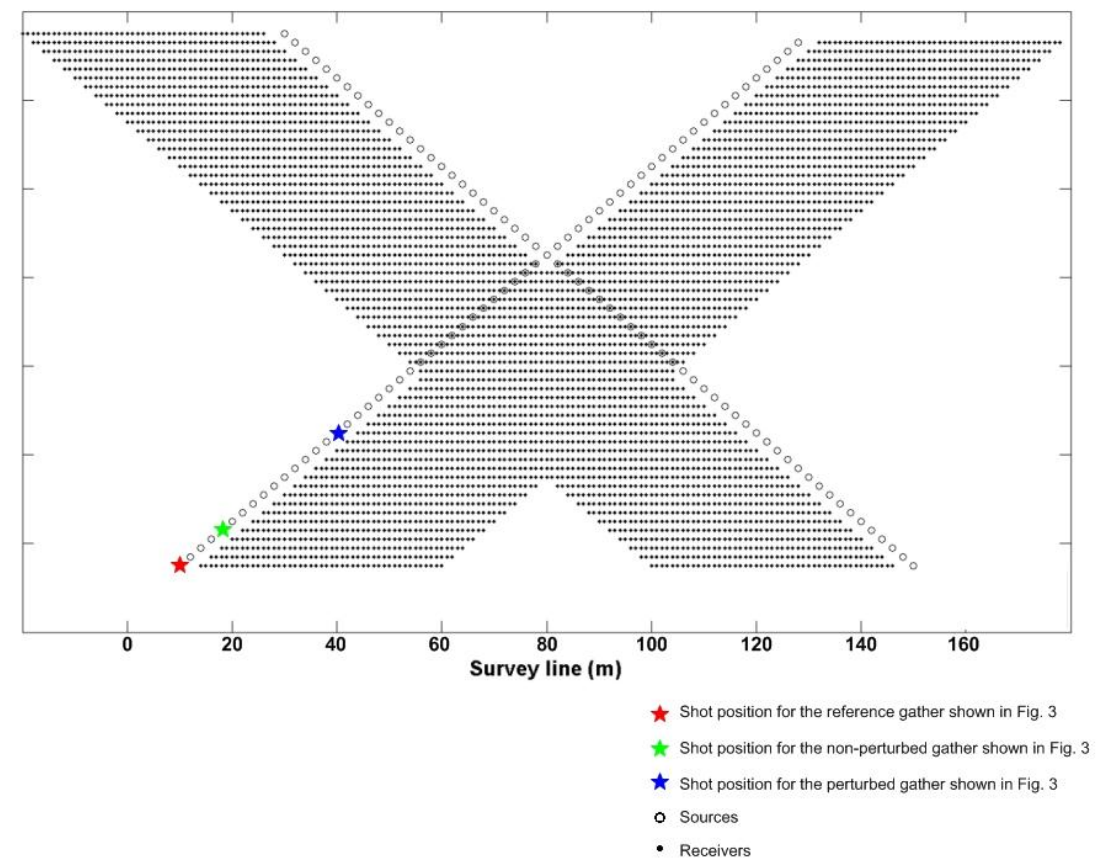

626 Figure. 1 


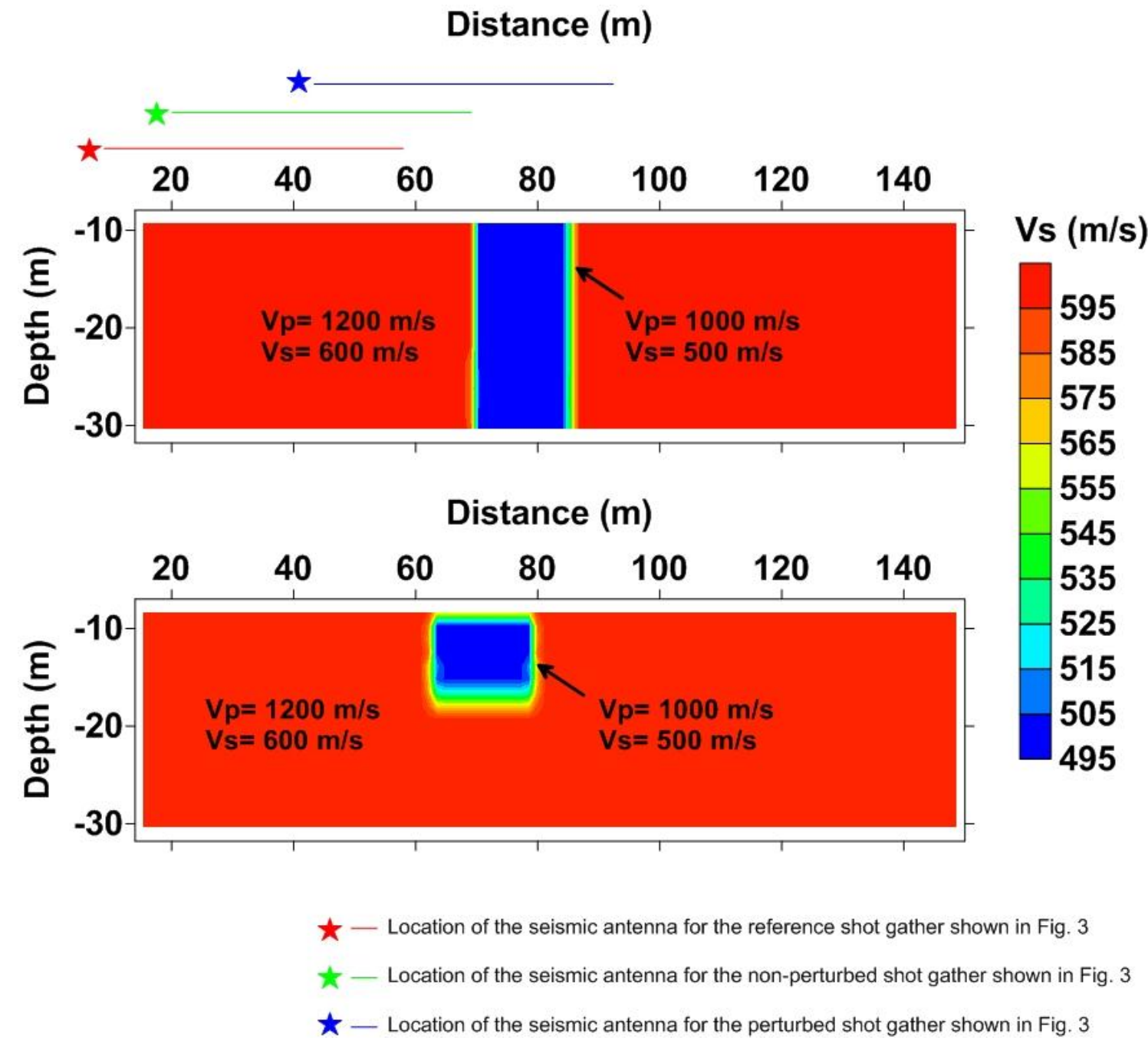

627

$\star$ - Location of the seismic antenna for the perturbed shot gather shown in Fig. 3

Figure. 2 

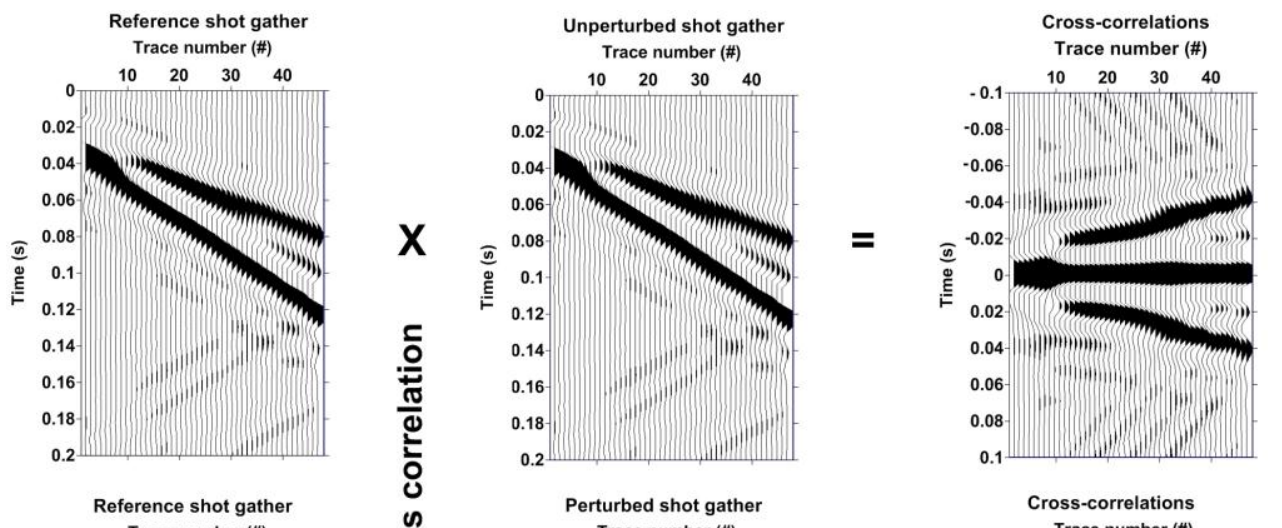

a
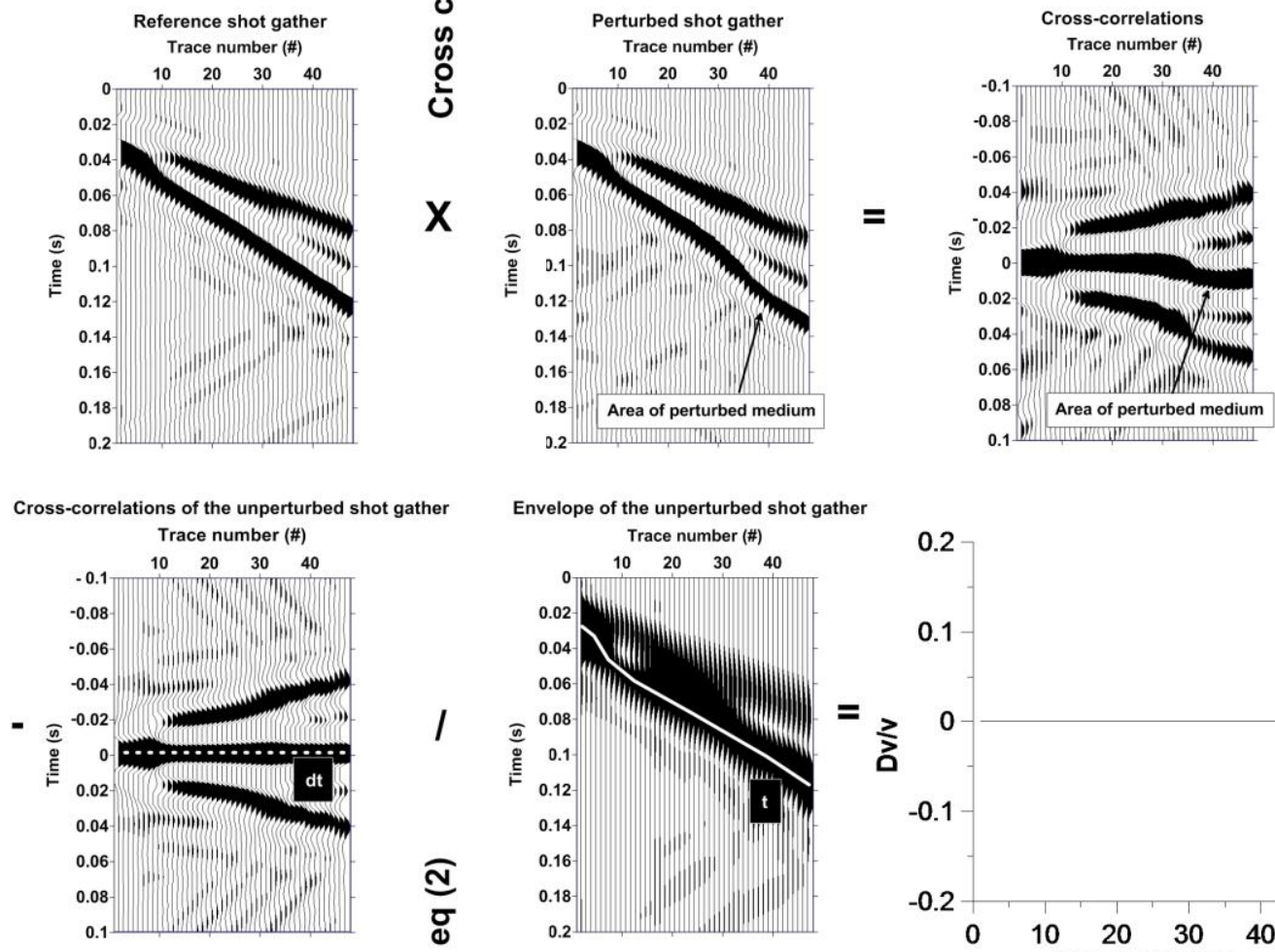

Envelope of the unperturbed shot gather

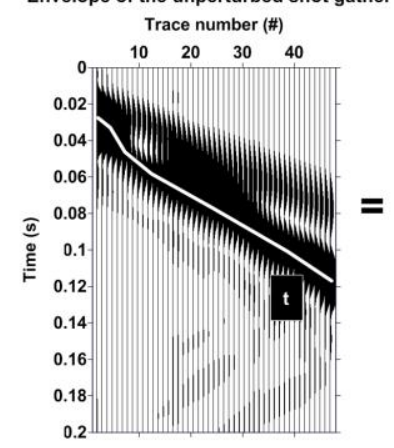

b
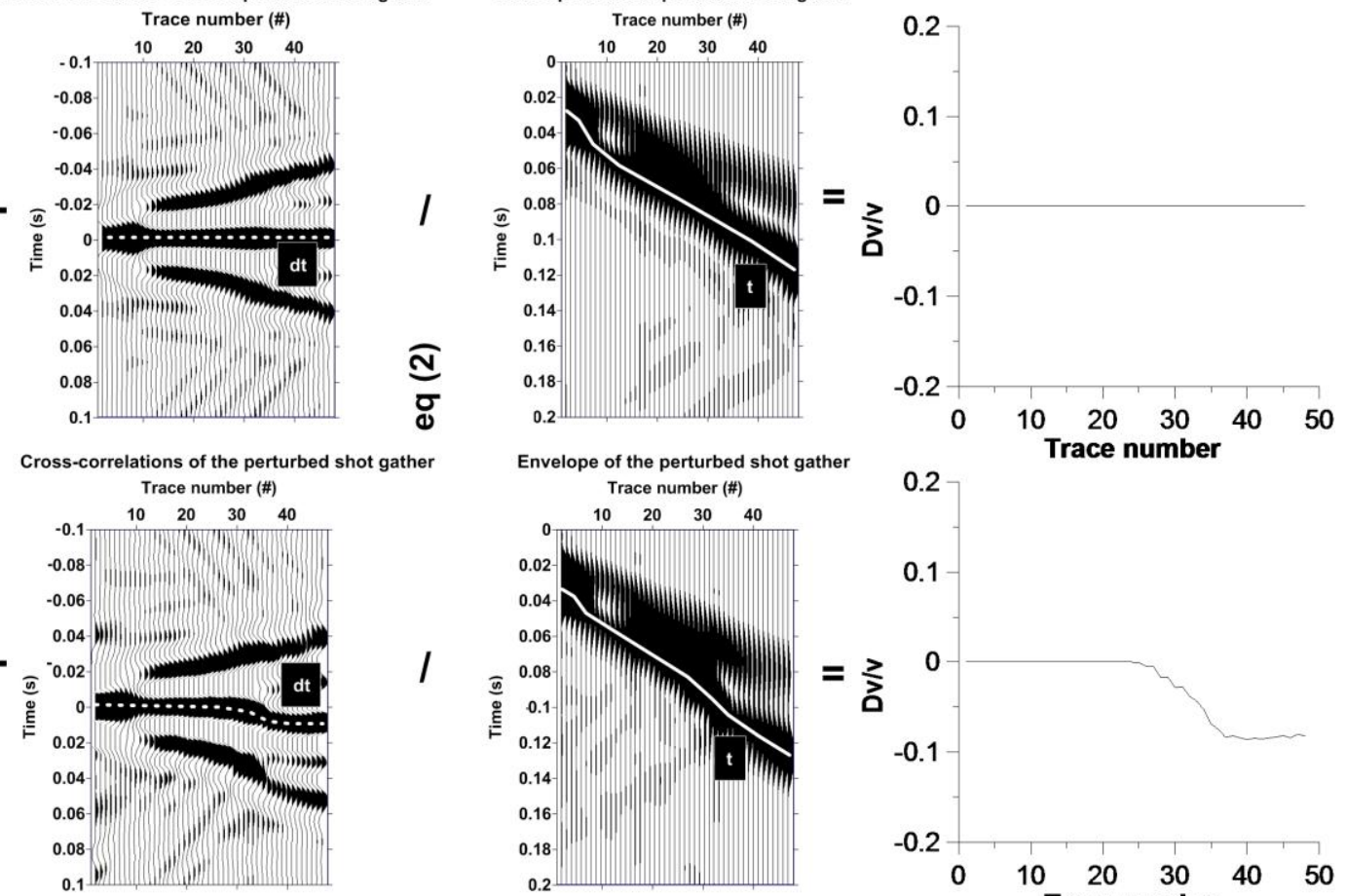

Figure. 3 

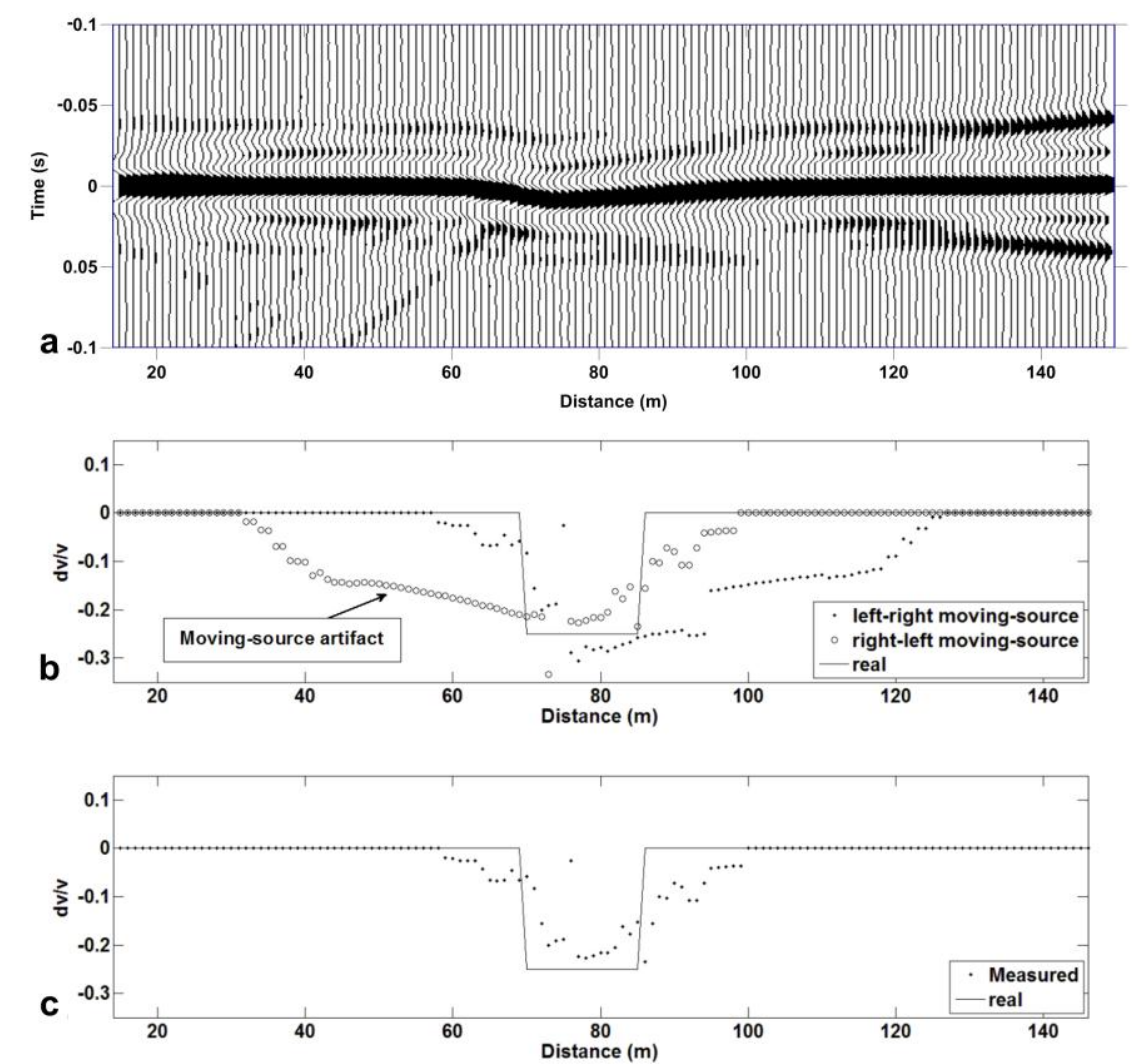

631

632 Figure. 4 


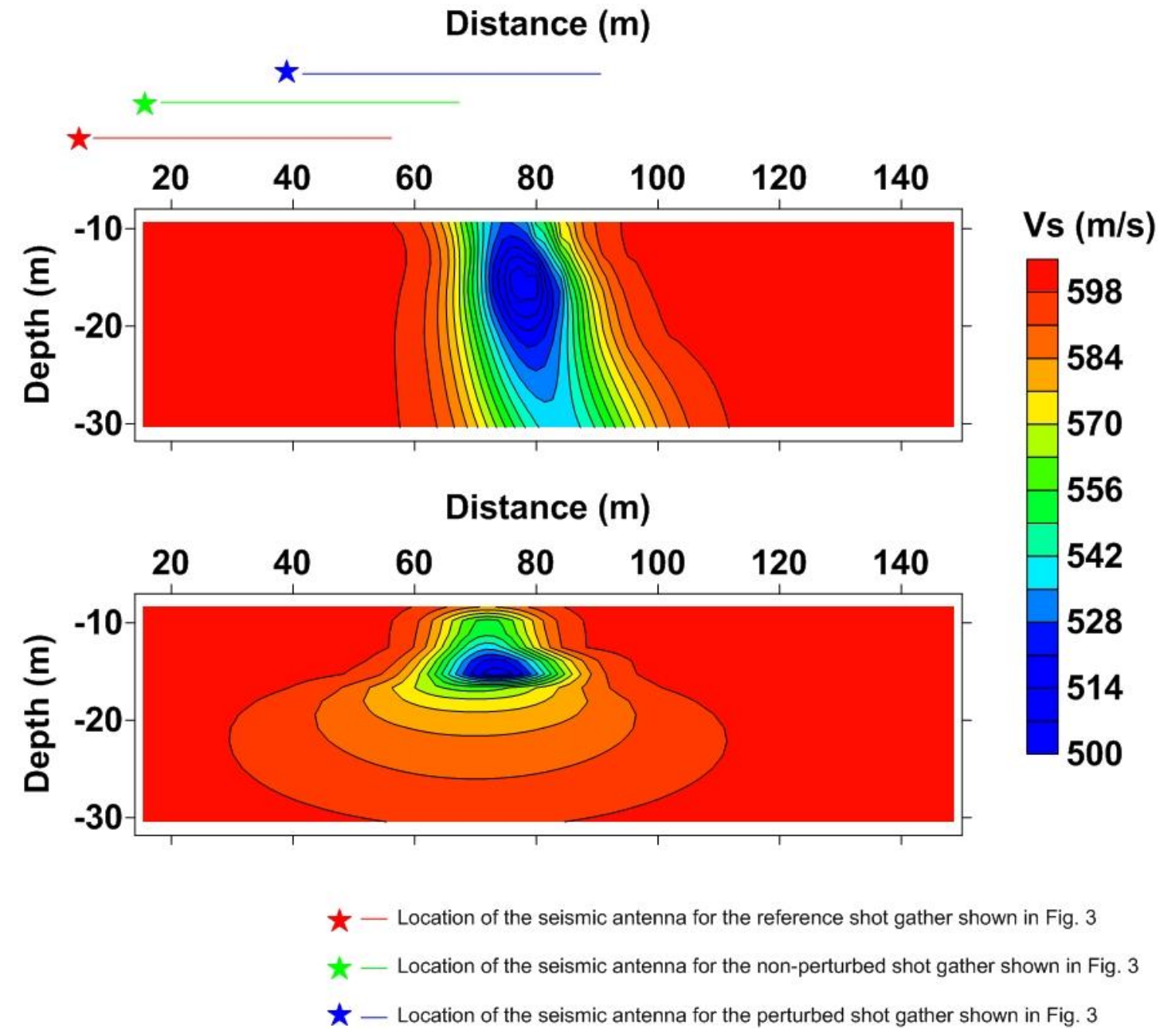

$634 \quad$ Figure. 5

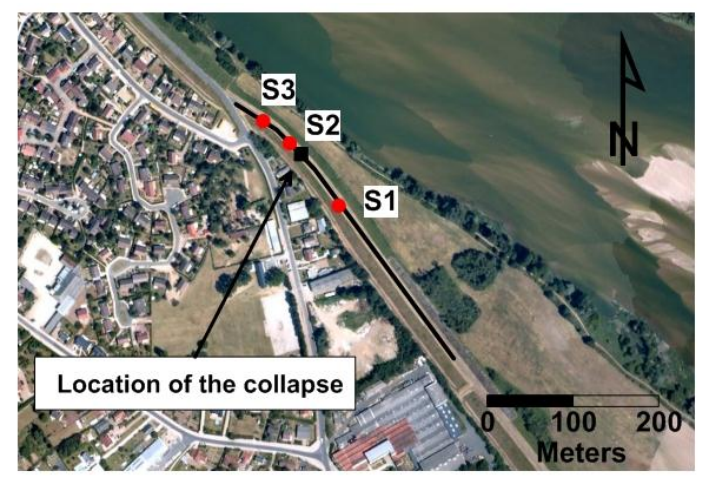

a

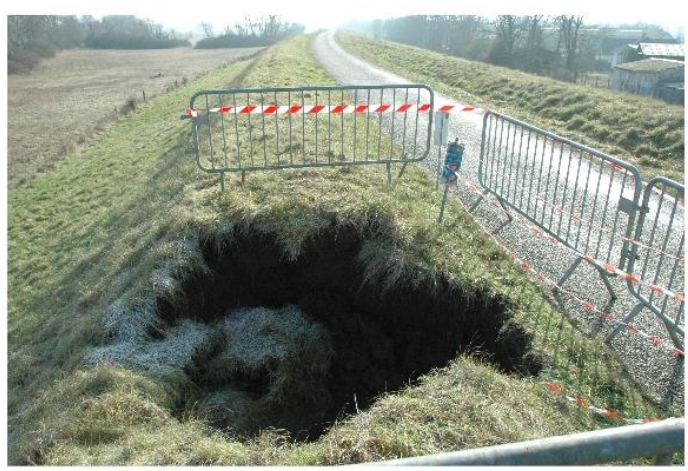

b

636 Figure. 6 


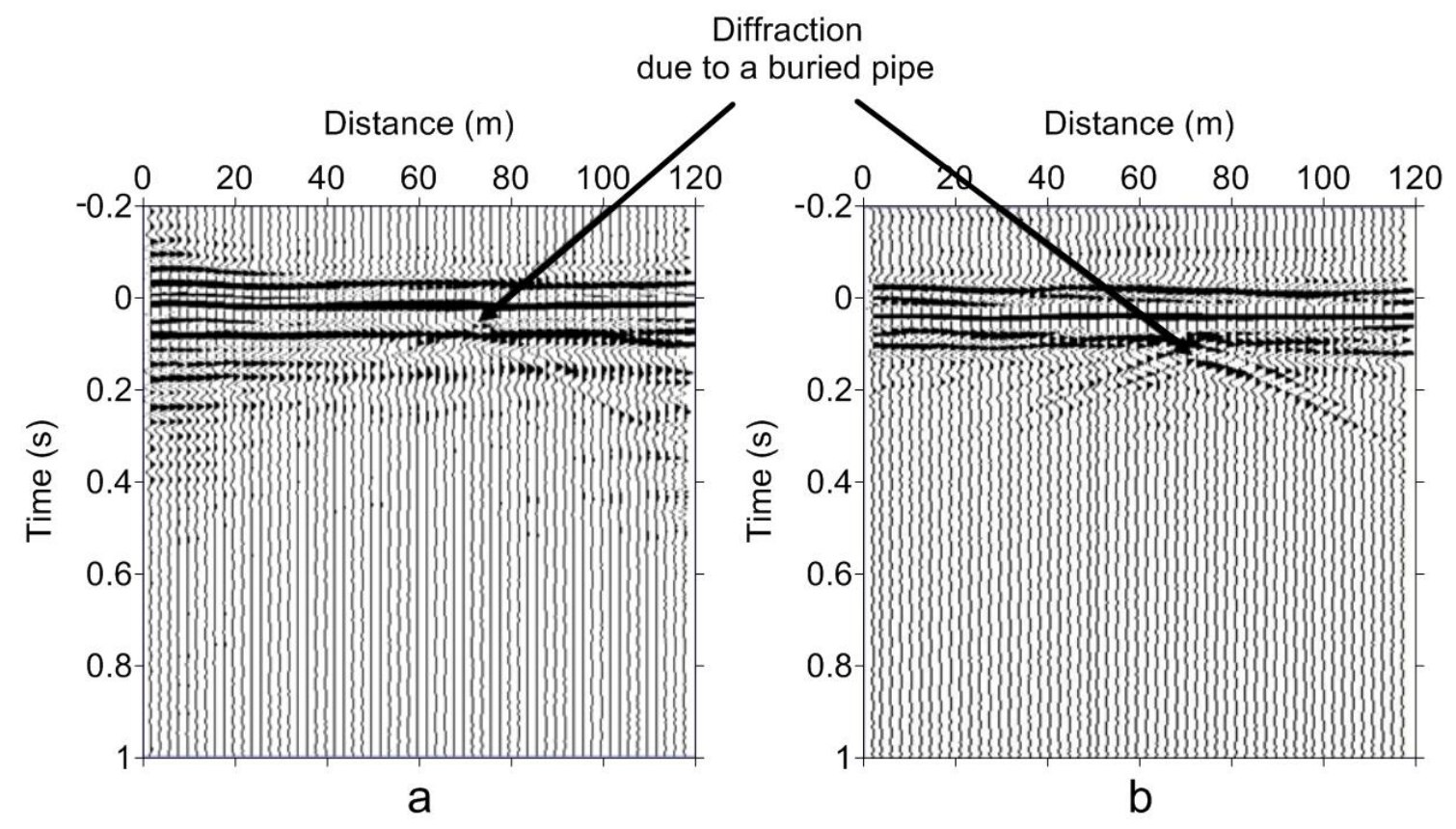

638 Figure. 7 


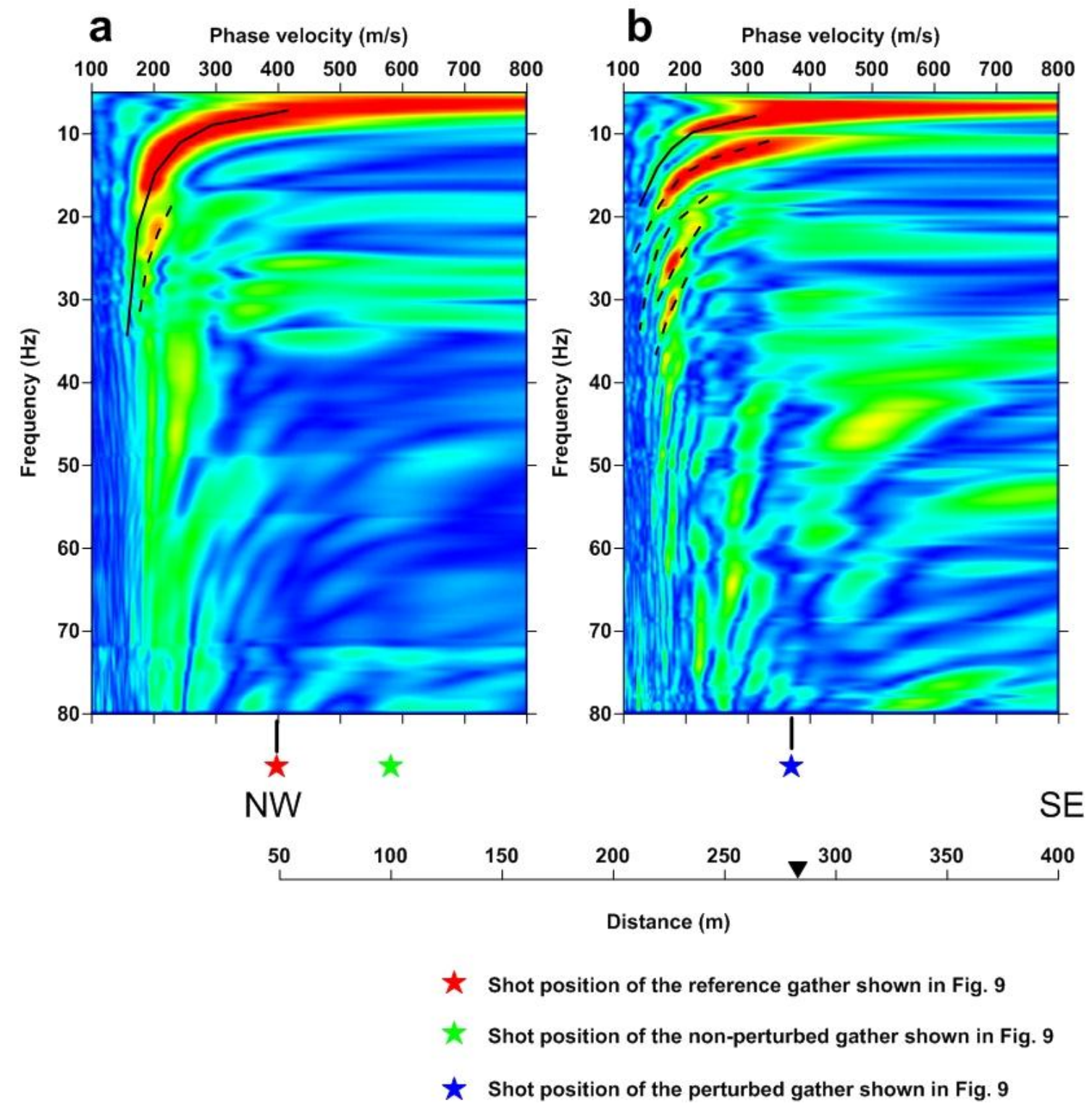

$640 \quad$ Figure. 8 

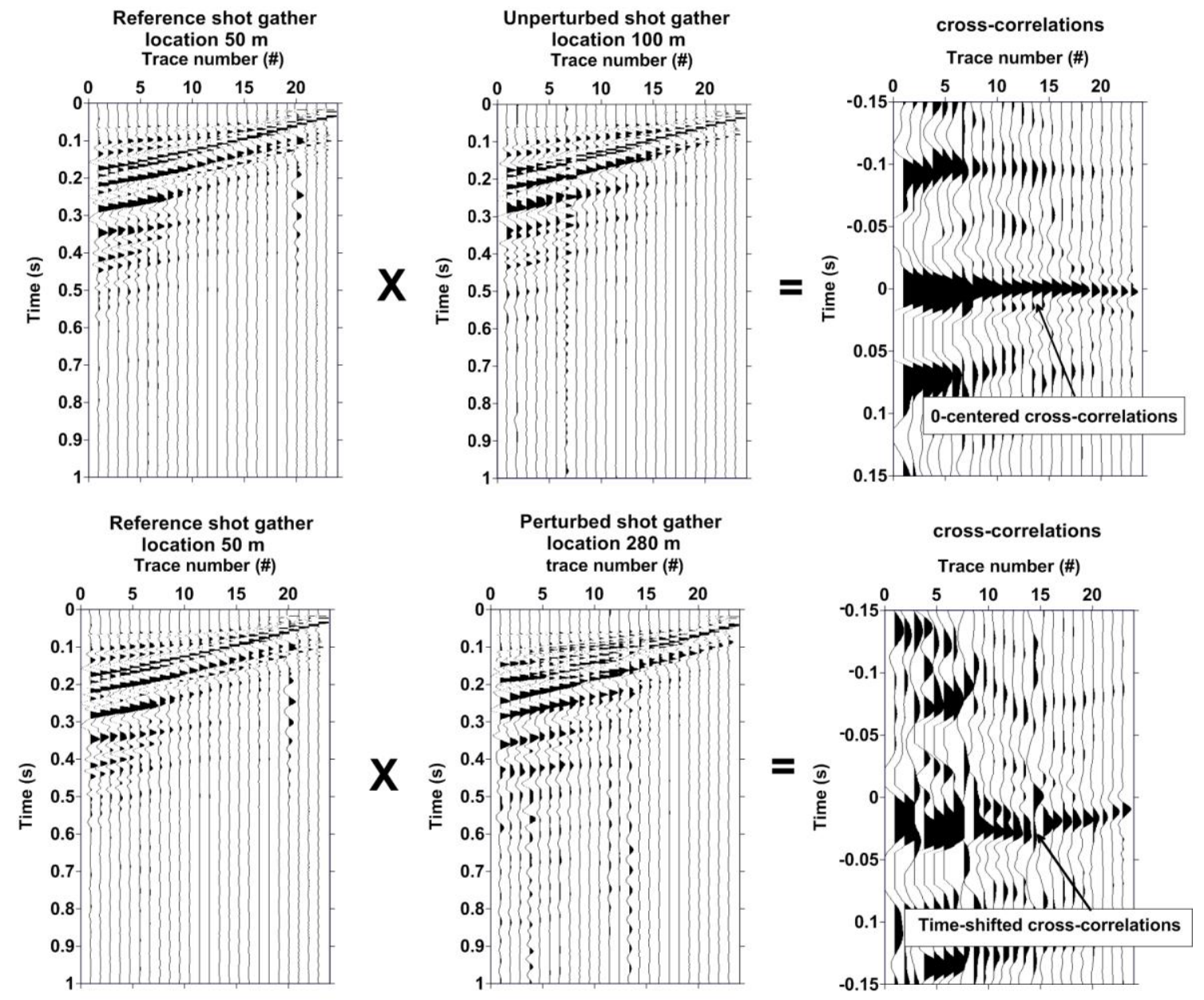

642 Figure. 9 


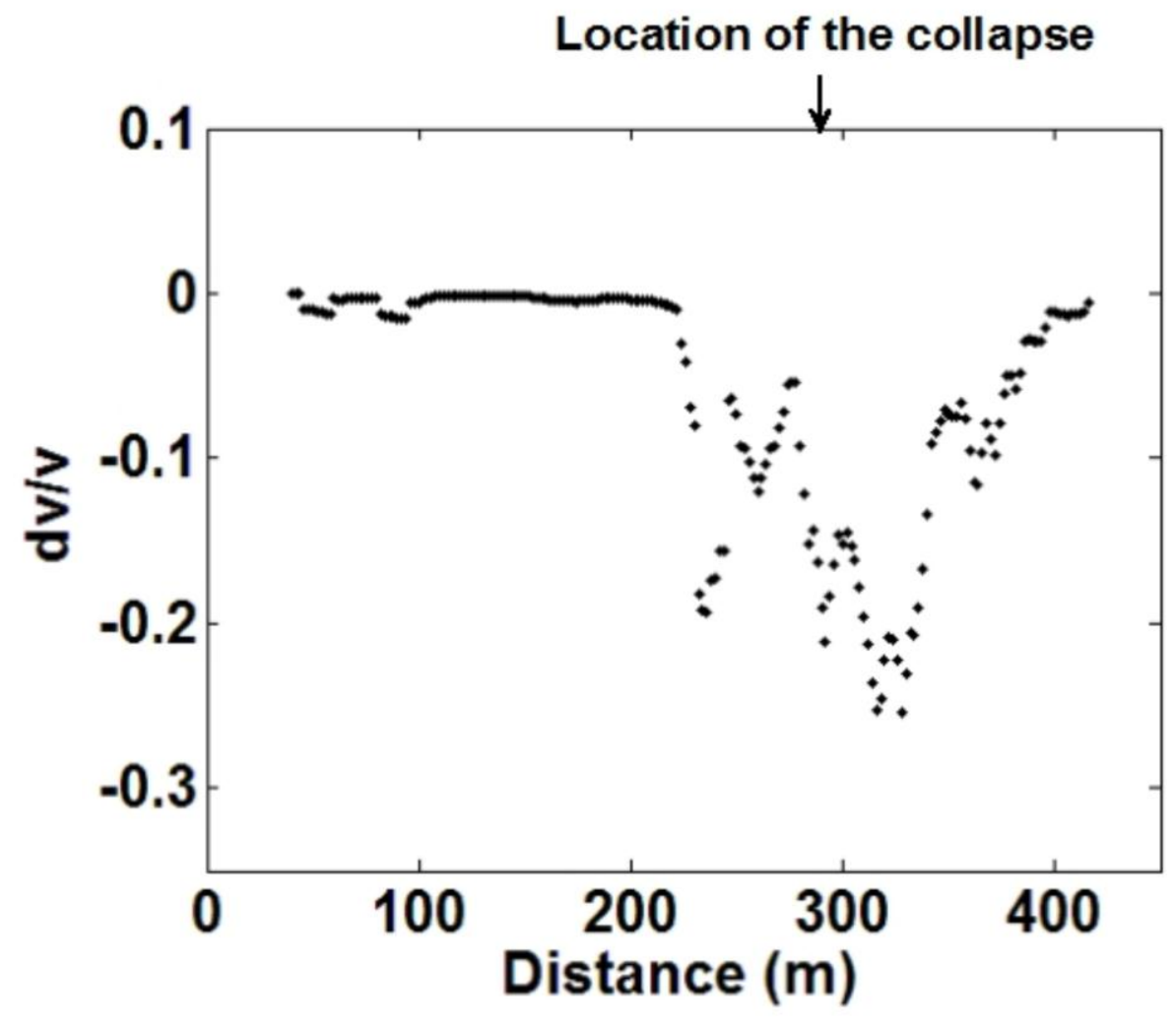

643

644 Figure. 10 

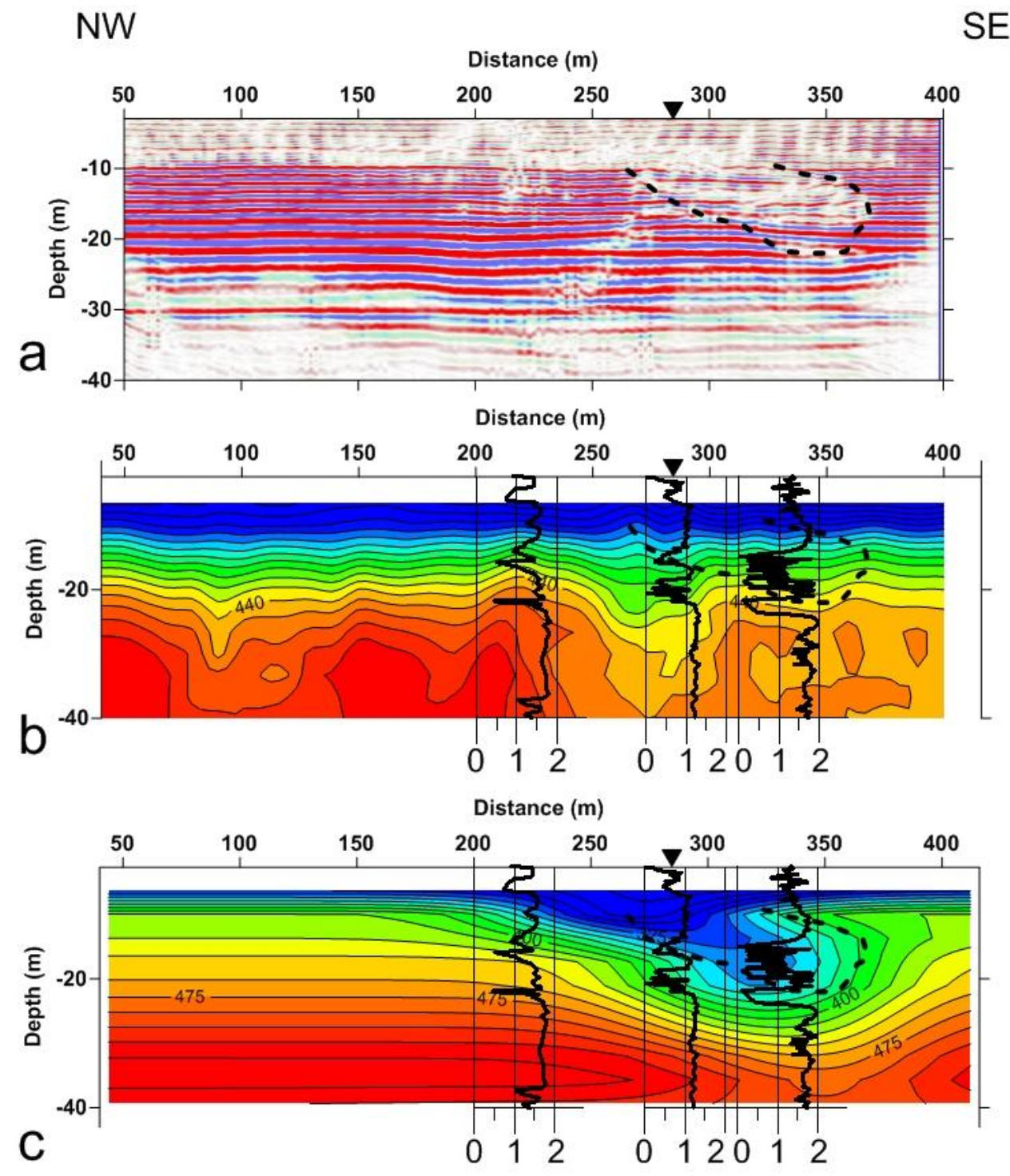

\begin{tabular}{l}
500 \\
-460 \\
-420 \\
\hline 380 \\
-340 \\
-300 \\
260 \\
220 \\
180 \\
140
\end{tabular}

645

646 Figure. 11 